\title{
Comparison of immune responses to intranasal and intrapulmonary vaccinations with the attenuated Mycoplasma hyopneumoniae 168 strain in pigs
}

\author{
Pengcheng $\mathrm{LI}^{1,2)}$, Yunfeng $\mathrm{LI}^{1}$, Guoqing SHAO ${ }^{3)}$, Qinghua $\mathrm{YU}^{1)}$ and Qian $\mathrm{YANG}^{1) *}$ \\ ${ }^{1)}$ College of Veterinary Medicine, Nanjing Agricultural University, Nanjing, PR China \\ ${ }^{2)}$ National Research Center of Veterinary Biologicals Engineering and Technology, Jiangsu Academy of Agricultural Science, Nanjing, \\ PR China \\ ${ }^{3)}$ Key Laboratory of Animal Diseases Diagnostic and Immunology, Institute of Veterinary Medicine, Jiangsu Academy of Agricultural \\ Science, Nanjing, PR China
}

(Received 9 March 2014/Accepted 20 December 2014/Published online in J-STAGE 30 January 2015)

ABSTRACT. The aim of this study was to evaluate the immune responses to intranasal and intrapulmonary vaccinations with the attenuated Mycoplasma hyopneumoniae (Mhp) 168 strain in the local respiratory tract in pigs. Twenty-four pigs were randomly divided into 4 groups: an intranasal immunization group, an intrapulmonary immunization group, an intramuscular immunization group and a control group. The levels of local respiratory tract cellular and humoral immune responses were investigated. The levels of interleukin (IL)- 6 in the early stage of immunization $(P<0.01)$, local specific secretory $\operatorname{IgA}(\operatorname{sg} \mathrm{A})$ in nasal swab samples $(P<0.01)$; and $\operatorname{IgA}$ - and $\operatorname{IgG}$-secreting cells in the nasal mucosa and trachea were higher after intranasal vaccination $(P<0.01)$ than in the control group. Interestingly, intrapulmonary immunization induced much stronger immune responses than intranasal immunization. Intrapulmonary immunization also significantly increased the secretion of IL-6 and local specific SIgA and the numbers of IgA- and IgG-secreting cells. The levels of IL-10 and interferon- $\gamma$ in the nasal swab samples and the numbers of $\mathrm{CD}^{+}$and $\mathrm{CD}^{+} \mathrm{T}$ lymphocytes in the lung and hilar lymph nodes were significantly increased by intrapulmonary immunization compared with those in the control group $(P<0.01)$. These data suggest that intrapulmonary immunization with attenuated $M h p$ is effective in evoking local cellular and humoral immune responses in the respiratory tract. Intrapulmonary immunization with Mhp may be a promising route for defense against Mhp in pigs.

KEY WORDS: attenuated Mycoplasma hyopneumoniae 168 strain, intranasal immunization, intrapulmonary immunization, respiratory tract, swine

doi: 10.1292/jvms.14-0123; J. Vet. Med. Sci. 77(5): 519-525, 2015

Mycoplasmal pneumonia of swine, caused by Mycoplasma hyopneumoniae (Mhp), is one of the most common and economically most important diseases of swine. The primary mycoplasmal infection often becomes complicated by secondary bacterial infections with Pasteurella multocida or Actinobacillus pleuropneumoniae or by viral infections with porcine circovirus type 2 , porcine parvovirus and porcine reproductive and respiratory syndrome virus (PRRSV), resulting in more severe lung lesions and production losses, including slow growth and poor feed conversion. The major routes of entry for the $M h p$ pathogen are the mucosal surfaces of the respiratory tract, and it spreads throughout herds by airborne transmission. The establishment of immune responses in the respiratory tract mucosa may play a critical role in preventing $M h p$ invasion [2]. In the upper respiratory tract, lymphoid tissues are present in the pig nose cavity, especially in the pharyngeal tonsils and tubal tonsils located in the posterior area. Intranasal vaccination could induce the production of cytokines and antibodies by

*Correspondence to: Yang, Q., College of Veterinary Medicine, Nanjing Agricultural University, Nanjing, PR China.

e-mail: zxbyq@njau.edu.cn

(C)2015 The Japanese Society of Veterinary Science

This is an open-access article distributed under the terms of the Creative Commons Attribution Non-Commercial No Derivatives (by-nc-nd) License $<$ http://creativecommons.org/licenses/by-nc-nd/3.0/>. these lymphoid tissues [11]. Recent studies have shown that intranasal immunization with an attenuated virus can induce effective immune responses, including against pseudorabies virus $(P R V)$ and PRRSV [4, 10, 24].

Recently, an attenuated Mhp 168 strain vaccine has been widely used to control Mhp spread in China. However, the protective effect of intramuscular immunization may be less than satisfactory because the pathogen only proliferates in the epithelium of the respiratory tract, so intramuscular immunization has been replaced with intrapulmonary immunization [26]. Intrapulmonary vaccination has considerable potential as a route of delivery [18], because it can lead to the stimulation of IgG-mediated immune protection in the alveoli and mucosal secretory $\operatorname{IgA}(\operatorname{sg} \mathrm{A})$-mediated immune protection in the conducting airways [12]. It is easier for the lung to elicit maximal local immune responses with low levels of antigen because it is located in the lower respiratory tract, which is sterile under ordinary conditions. Wee et al. [22] found that intrapulmonary immunization with extremely low antigen doses (0.04 g influenza antigen) induced serum antibody levels equivalent to those resulting from the current human vaccine equivalent (15 g antigen influenza without adjuvant, administered subcutaneously). However, few researchers have ventured into the field of intrapulmonary vaccination.

Intranasal vaccination and intrapulmonary vaccination induce upper respiratory tract and lower respiratory tract 
Table 1. Experimental groups and administration strategies

\begin{tabular}{llll}
\hline Group & $\begin{array}{c}\text { Placebo antigen } \\
\text { (no adjuvants) }\end{array}$ & $\begin{array}{c}\text { Age } \\
\text { at administration }\end{array}$ & $\begin{array}{c}\text { Route of } \\
\text { administration }\end{array}$ \\
\hline Control & Phys saline & 7 and 10 days & Intranasal \\
Mhp-IM & Mhp 168,10 $10^{6} \mathrm{CCU}$ & 7 days & Intramuscular \\
Mhp-IN & Mhp 168,10 $10^{6} \mathrm{CCU}$ & 7 and 10 days & Intranasal \\
Mhp-IP & Mhp 168,106 $\mathrm{CCU}$ & 7 days & Intrapulmonary \\
\hline
\end{tabular}

immune responses, respectively. However, the exact immunological mechanisms of this attenuated Mhp 168 strain vaccine are not very clear. In this study, we inoculated piglets with the attenuated $M$. hyopneumoniae 168 strain vaccine by intranasal, intrapulmonary and intramuscular routes. The local mucosal and cell-mediated immune responses were evaluated, and then, the intranasal and intrapulmonary vaccinations were compared.

\section{MATERIALS AND METHODS}

Vaccine strain: The attenuated Mhp 168 strain (titer $1 \times$ $10^{6}$ color changing units $(\mathrm{CCU}) / \mathrm{m} l$ ) was purchased from Nanjing Tianbang Bio-industry Co. (Nanjing, PR China). The safety of the attenuated $M h p 168$ strain was certified by an animal regression test [26].

Animals and experimental design: Twenty-four newborn cross-bred (Landrace $\times$ Large Yorkshire) piglets, from 4 litters were housed with their sow at Sentai Hogpen Farm (Anhui, PR China), which was free of $M h p$. The piglets were healthy and unvaccinated with any $M h p$ vaccines, and they were fed without antibiotics. The piglets were divided randomly into 4 groups (each group consisted of 6 pigs); and were immunized as shown in Table 1. Among them, 6 piglets from Group IP received $1 \mathrm{ml}\left(10^{6} \mathrm{CCU}\right) \mathrm{Mhp} 168$ strain each by the intrapulmonary through the Su-qi acupoint between the 2 nd and 3rd ribs behind the right scapula [26].

Collection and preparation of samples: Nasal swabs were collected from pigs on $0,3,5,7,14,21,28$ and 35 days post immunization (DPI) by inserting cotton wool swabs deeply into 2 nasal cavities. Each swab was placed in a tube that contained $1 \mathrm{~m} l$ of sterile phosphate-buffered saline (PBS) and stored at $4-8^{\circ} \mathrm{C}$ overnight. The swab suspensions were centrifuged at 10,000 $\mathrm{g}$ for $5 \mathrm{~min}$, and the supernatant was collected for detection of anti-Mhp sIgA and cytokines IL-6, IL-10 and IFN- $\gamma$. Nasal swabs from specific pathogen-free (SPF) piglets were collected and used as negative controls in a $\operatorname{sIgA}$ enzyme-linked immunosorbent assay (ELISA), and piglets challenged artificially with $M h p$ were used as the positive control.

All pigs were slaughtered at 6 weeks after the first vaccination. Tissue samples from the nasal mucosa (posterior part of nasal cavity, around pharyngeal tonsil and the tubal tonsil), trachea, tracheal bifurcation, lung and hilar lymph node (HLN) were taken respectively and fixed in Bouin's liquid or liquid nitrogen for histological and immunohistochemical detection. Our study was carried out according to China's animal welfare guidelines.
$\mathbf{A}$

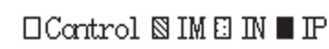

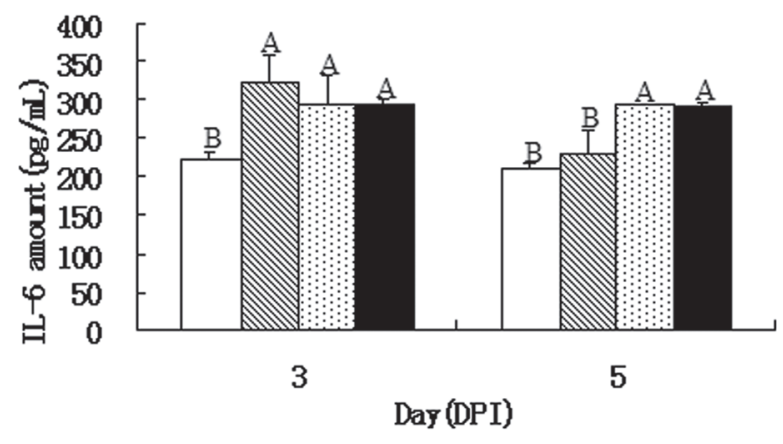

$\mathbf{B}$

$\square$ Control $\mathbb{M} \mathbb{M}[\mathbb{N} \mathbf{I P}$

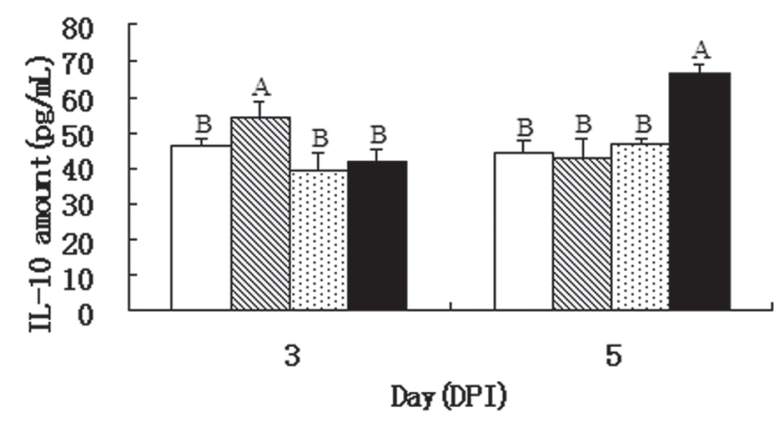

C $\square$ Control $\mathbb{Q}$ IM $\mathrm{O}$ IN $\mathbf{~ I P}$

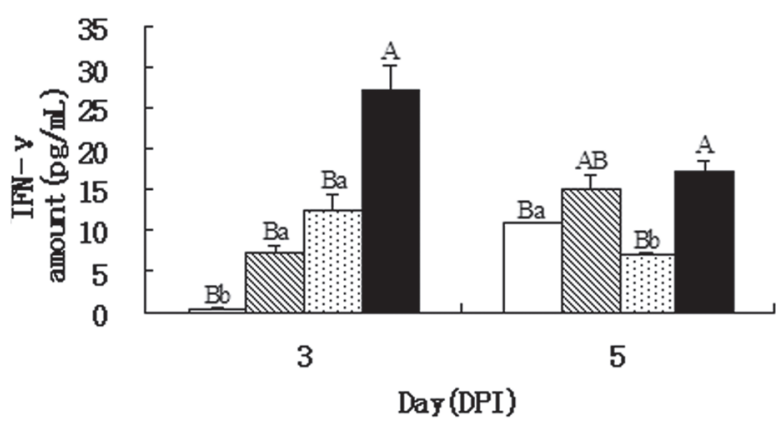

Fig. 1. Cytokine levels (A, IL-6; B, IL-10; C, IFN- $\gamma$ ) in nasal swabs collected three and 5 days after the first inoculation. Results are presented as the mean \pm SEM. The level of significance is identified by the $\mathrm{P}$ value. Capital letters indicate differences at $P<0.01$, and small letters indicate differences at $P<0.05$

IL-6, IL-10 and IFN- $\gamma$ detection: Porcine IL-6, IL-10 and IFN- $\gamma$ in nasal secretions were detected at 3 and 5 DPI following the manufacturer's instructions for porcine IL-6 (Cat. no.: P6000, R\&D Systems, Minneapolis, MN, U.S.A.); and IL-10 (Cat. no.: P1000, R\&D Systems) ELISA kits and for a pig IFN- $\gamma$ Platinum ELISA Kit (Cat. no.: BMS671, eBioscience, San Diego, CA, U.S.A.).

Immunohistochemical examination for $C D 4^{+}$and $C D 8^{+} T$ lymphocytes: The fixed samples were embedded in paraffin 
and sectioned at $8 \mu \mathrm{m}$ thickness, and then, all were deparaffinized to water. The sections were neutralized by $3 \% \mathrm{H}_{2} \mathrm{O}_{2}$ in PBS for $10 \mathrm{~min}$; and then rinsed in distilled water for 15 min. The sections were then immersed in $0.01 \mathrm{M}$ citric acid salt buffer with a liquid hydrogen ion index of 6.0. The sections were boiled in a microwave oven and then cooled, and this process was repeated $5 \mathrm{~min}$ later, followed by a rinse in PBS (pH 7.2-7.6) for $15 \mathrm{~min}$. The sections were treated with $5 \%$ BSA in PBS for 20 min to block nonspecific binding, stained separately with mouse anti-porcine CD4 (or CD8) antibody (Codes: APG420 and APG 820, Antigenix America, Huntington Station, NY, U.S.A.) at $4^{\circ} \mathrm{C}$ overnight; and then rinsed in PBS ( $\mathrm{pH} 7.2-7.6$ ) for $15 \mathrm{~min}$. Next, sections were incubated with goat anti-mouse IgG-Biotin (Boster, Wuhan, PR China) for $20 \mathrm{~min}$ at $37^{\circ} \mathrm{C}$ and rinsed in PBS ( $\mathrm{pH}$ 7.2-7.6) for $20 \mathrm{~min}$. The sections were visualized with metal-enhanced diaminobenzidine (DAB; Sigma). Incubation was performed in a moist chamber. Control staining was carried out simultaneously, in which the first antibody was replaced with normal mouse serum. The sections were observed under an Olympus BH-2 microscope, and 10 different fields were chosen per section, with 5 sections per pig in each group; the data for the positive cells were calculated per region. The regions that contained $\mathrm{CD} 4^{+}$and $\mathrm{CD}^{+} \mathrm{T}$ lymphocytes were counted by the Image Pro-plus analysis program (Cambridge, U.K.), and the results were used in the statistical analysis.

Immunohistochemical examination for IgA- and IgGsecreting cells: The experimental process was the same as that above, except that the mouse anti-porcine CD4 (or CD8) antibody was replaced with a rabbit anti-porcine IgA (or IgG) antibody and the goat anti-mouse IgG-Biotin was replaced with staphylococcal protein A-horseradish peroxidase (SPA-HRP).

Specific sIgA detection: Anti-Mhp sIgA was detected by indirect ELISA as an estimate of mucosal immunity levels at 7, 14, 21, 28 and $35 \mathrm{DPI}$. Briefly, polystyrene plates were coated overnight at $4^{\circ} \mathrm{C}$ with $5 \mu \mathrm{g}$ per well of Mhp P97R1 protein (supplied by Jiangsu Academy of Agricultural Sciences, China) diluted in carbonate-bicarbonate buffer (pH 9.6) [5]. Then, the plates were blocked with 1\% BSA in PBS. After three PBS-T washes, $100 \mu l$ swab suspensions, in triplicate, were added to the plates. The samples were incubated for $2 \mathrm{hr}$ at $37^{\circ} \mathrm{C}$ and washed three times with PBS-T, goat anti-pig IgA (Cat. no.: A100-102P, Bethyl Laboratories, Montgomery, TX, U.S.A.) diluted 1:8,000 in 1\% BSA was added, and samples were incubated at $37^{\circ} \mathrm{C}$ for $1 \mathrm{hr}$. After repeated washes, rabbit anti-goat IgG conjugated with horseradish peroxidase $(1: 10,000$ in $1 \% \mathrm{BSA})$ was added, and the samples were incubated at $37^{\circ} \mathrm{C}$ for $1 \mathrm{hr}$. After three PBS-T washes, a colorimetric reaction was induced by the addition of $100 \mu l$ of the chromogenic substrate $(0.1 \mathrm{mg} / \mathrm{m} l$ tetramethylbenzidine (TMB; Sigma), $100 \mathrm{mM}$ acetate buffer, $\mathrm{pH}$ 5.6 , and $1 \mathrm{mM}$ urea hydrogen peroxide) for $10 \mathrm{~min}$ at $37^{\circ} \mathrm{C}$. Color development was stopped with $50 \mu l \mathrm{H}_{2} \mathrm{SO}_{4}(2 \mathrm{M})$, and the optical density at $450 \mathrm{~nm}$ (OD450) was recorded using an universal ELx800 Absorbance Reader (Bio-Tek Instruments, Inc., Winooski, VT, U.S.A.). The experimental conditions given above were optimized to determine the highest OD450 ratio between positive and negative samples (P/N value). The $\mathrm{S} / \mathrm{P}$ value was calculated by the following formula: $\mathrm{S} / P=(\mathrm{OD} 450$ of sample $-\mathrm{OD} 450$ of negative control)/(OD450 of standard positive control - OD450 of negative control).

Statistics: All data were expressed as the mean \pm SEM. Experimental values were analyzed by analysis of variance (ANOVA). In the figures, the level of significance is identified by the $P$ value. Capital letters indicate differences at $P<0.01$, and small letters indicate differences at $P<0.05$.

\section{RESULTS}

Changes in the cytokines $I L-6, I L-10$ and IFN- $\gamma$ : As shown in Fig. 1, intranasal immunization and intrapulmonary immunization with the attenuated $M h p$ (without adjuvant) significantly increased the secretion of IL-6 and IFN- $\gamma$ at 3 DPI compared with the control group $(P<0.05$ and $P<0.01$, respectively), and intramuscular immunization with $M h p$ increased the secretion of IL-10 $(P<0.01)$. However, the secretion of IL-10 after intranasal immunization or intrapulmonary immunization did not differ from that in the control group. The level of IFN- $\gamma$ after immunization via the intrapulmonary route was much higher than after immunization via the other routes $(P<0.01)$. Intrapulmonary immunization with $M h p$ significantly increased the secretion of IL-6, IL-10 and IFN- $\gamma$ at 5 DPI compared with the other groups $(P<0.01)$. The levels of IL-6 were also significantly increased after intranasal immunization $(P<0.01)$, and the levels of IFN- $\gamma$ were increased after intramuscular immunization $(P<0.01)$. These three acute phase markers (cytokines) were not detected after 7 DPI (data not shown).

Changes in $\mathrm{CD}^{+}$and $C D 8^{+}$T lymphocytes: The CD4 ${ }^{+}$ and $\mathrm{CD}^{+} \mathrm{T}$ lymphocytes in the lung and hilar lymph nodes (HLNs) were round or elliptical in shape, and the cell membranes were stained a deep yellow-brown color (Fig. 2). In the lung, the $\mathrm{CD}^{+}$and $\mathrm{CD} 8^{+} \mathrm{T}$ lymphocytes were dispersed widely in the alveolar septum. In the HLNs, the $\mathrm{CD}^{+}$and $\mathrm{CD}^{+} \mathrm{T}$ lymphocytes were distributed mainly between the lymphatic nodules, although a few cells were dispersed in the cortical region. The numbers of $\mathrm{CD}^{+}$and $\mathrm{CD} 8^{+} \mathrm{T}$ cells increased significantly in the lung after intramuscular and intrapulmonary immunization compared with the levels in the other groups $(P<0.01) . \mathrm{CD}^{+} \mathrm{T}$ cells increased significantly in the HLNs after intrapulmonary immunization compared with the levels in the other groups $(P<0.01)$. The numbers of $\mathrm{CD}^{+}$and $\mathrm{CD}^{+} \mathrm{T}$ cells in the lung and HLNs did not change after intranasal immunization compared with those in the control group (Fig. 2).

Changes in IgA- and IgG-secreting cells: The IgA- and IgG-secreting cells in the nasal mucosa and trachea were distributed in the lamina propria and also surrounding the tracheal glands, and the lateral surface of the tracheal epithelium was strongly positively stained for these immunoglobulins (Fig. 3). The areas of IgA- and IgG-secreting cells in the trachea and IgA-secreting cells in the nasal mucosa increased significantly after intrapulmonary, intranasal; or intramuscu- 

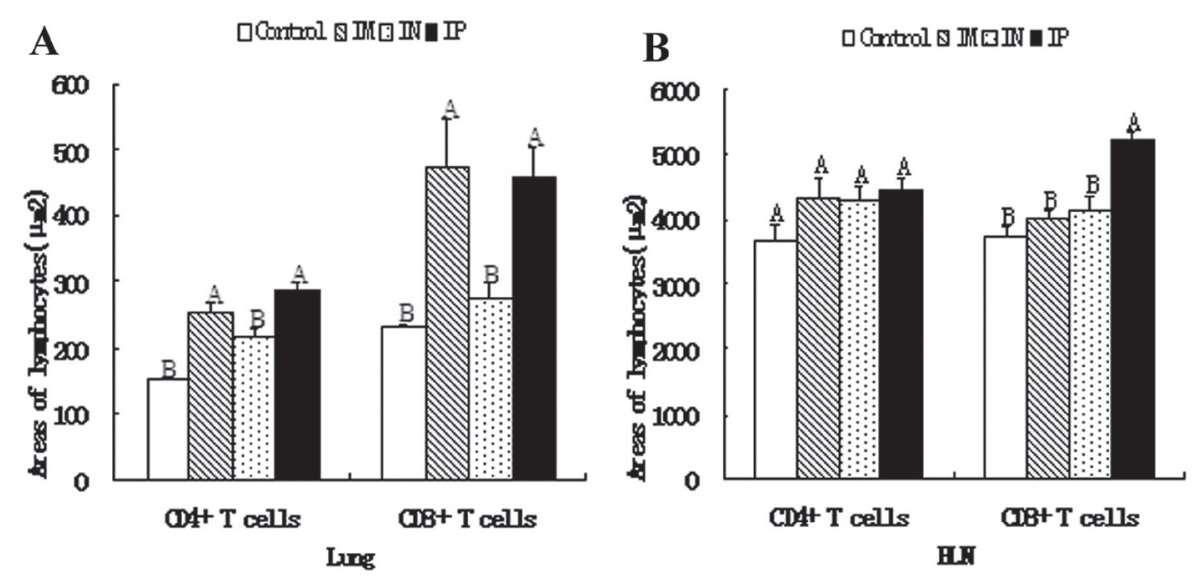

C

D
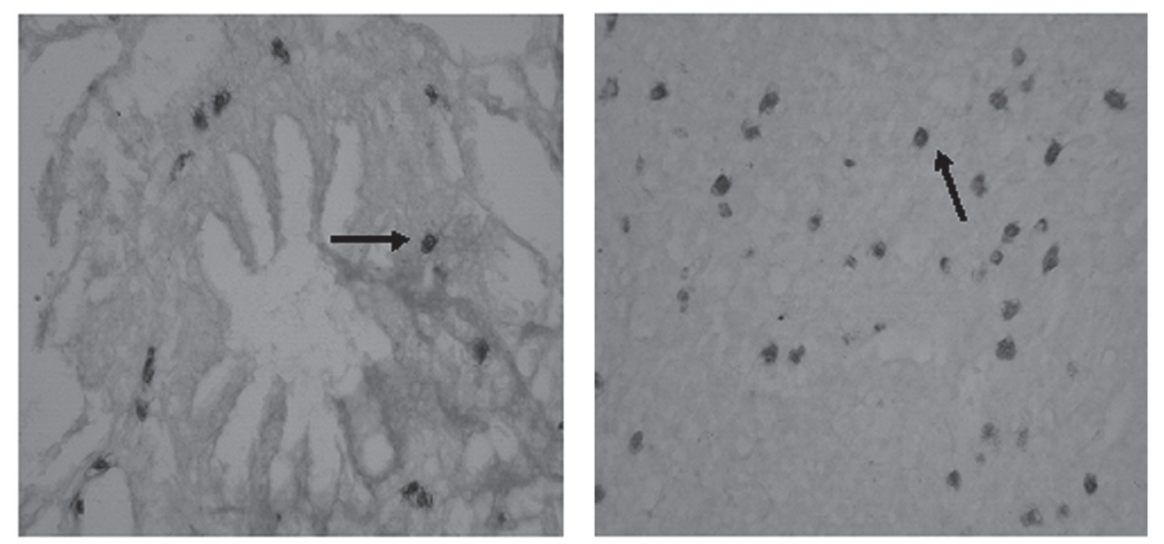

Fig. 2. The changes in the distribution and numbers of CD4+ and CD8+ T lymphocytes in the lung $(A, C)$ and hilar lymph nodes (B, D). Results were presented as mean \pm SEM. The level of significance is identified by the $P$ value. Capital letters indicate differences at $P<0.01$, and small letters indicate differences at $P<0.05$.

lar immunization $(P<0.01)$. The areas of IgG-secreting cells in the nasal mucosa increased significantly after intranasal or intramuscular immunization with the attenuated Mhp 168 strain compared with the other groups $(P<0.01)$.

Changes in local Mhp-specific sIgA responses: As shown in Fig. 4, specific anti-Mhp sIgA in the respiratory tract was measured at 7, 14, 21, 28; and 35 DPI. Intrapulmonary, intranasal or intramuscular immunization with the attenuated Mhp 168 strain significantly increased the levels of specific SIgA at 7, 14, 21 and 28 DPI compared with those in the control group $(P<0.01)$, and intrapulmonary immunization with $M h p$ also significantly increased the level of $\operatorname{sgA}$ at 35 DPI $(P<0.01)$. Intrapulmonary immunization with $M h p$ significantly increased the levels of $\operatorname{sgA}$ at 7, 21 and 35 DPI compared with the levels in the intranasal and intramuscular vaccination groups $(P<0.01)$.

\section{DISCUSSION}

Intranasal immunization can prevent the occurrence of respiratory infectious diseases, such as human influenza [18].
In recent years, intranasal vaccination has also gained credibility in preventing respiratory infectious diseases in pigs $[1,4,16]$. In this study, intranasal vaccination increased the levels of local cellular and humoral immunity in the respiratory tract. Interestingly, intrapulmonary vaccination induced significantly greater immune responses than intranasal vaccination. The surface area of the nasal mucosa is very limited and is only $150 \mathrm{~cm}^{2}$ in humans, whereas the lung has a much larger surface area (almost $140 \mathrm{~m}^{2}$ ) [14]. There are also a greater number of capillaries in the lung, which store many lymphocytes, and the number of lymphocytes in the lung is equal to the number in Peyer's patches in pigs [15]. The efficacy of a mucosal vaccine is achieved by prolonging the contact between the antigen and the mucosal surface. Once it enters the lung, the antigen will remain there for a long time, prolonging the stimulation of the local mucosal immune response. Therefore, intrapulmonary vaccination is a potentially effective immunization route, although relevant information about it is very limited [18]. Because Mhp only causes damage to the respiratory tract, the lung is an optimal target tissue. Therefore, intrapulmonary and intranasal im- 
$\mathbf{A}$

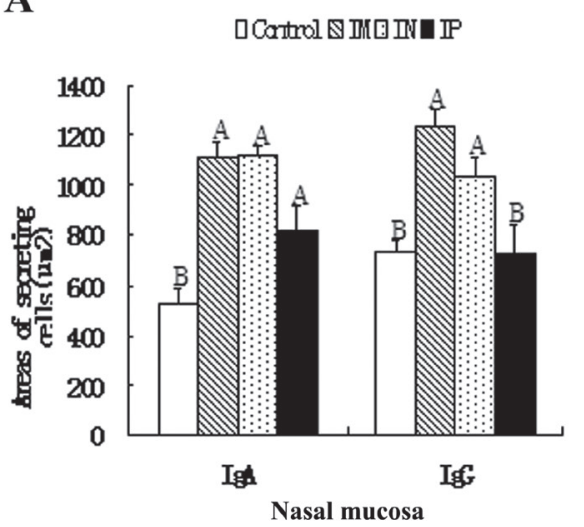

C

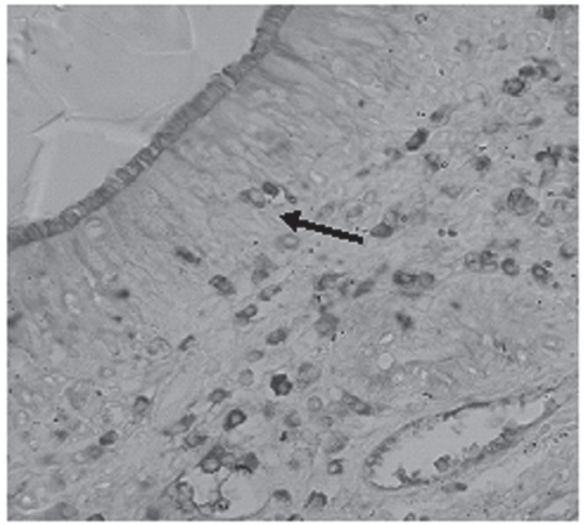

B

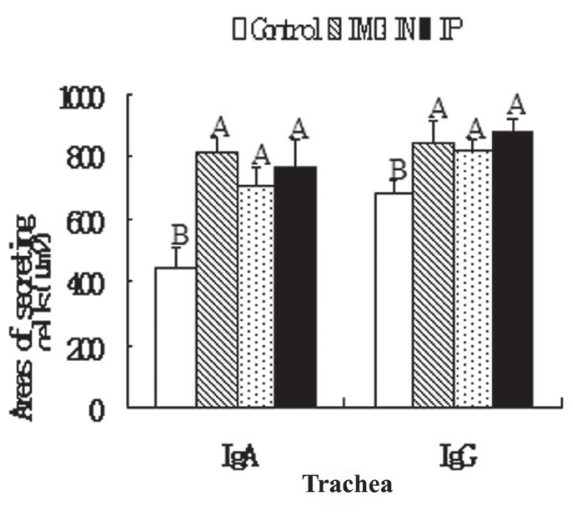

D

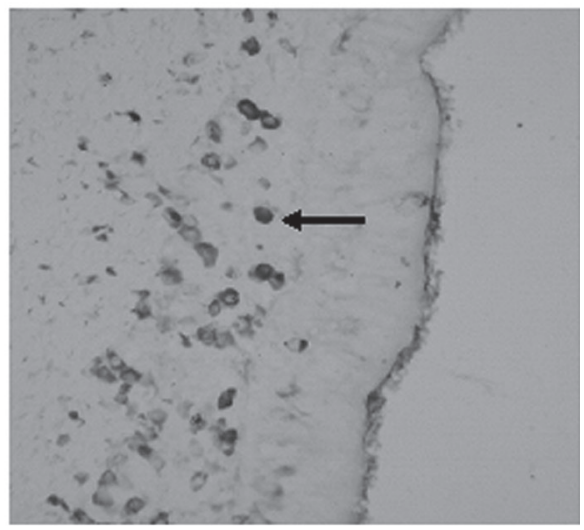

Fig. 3. The changes in the distribution and numbers of IgA- and IgG-secreting cells in the nasal mu$\operatorname{cosa}(A, C)$ and trachea $(B, D)$. Results are presented as the mean \pm SEM. The level of significance is identified by the $P$ value. Capital letters indicate differences at $P<0.01$, and small letters indicate differences at $P<0.05$.

$\square$ Control $\mathbb{B}$ IM $⿴ 囗 十$ IN $\square$ IP

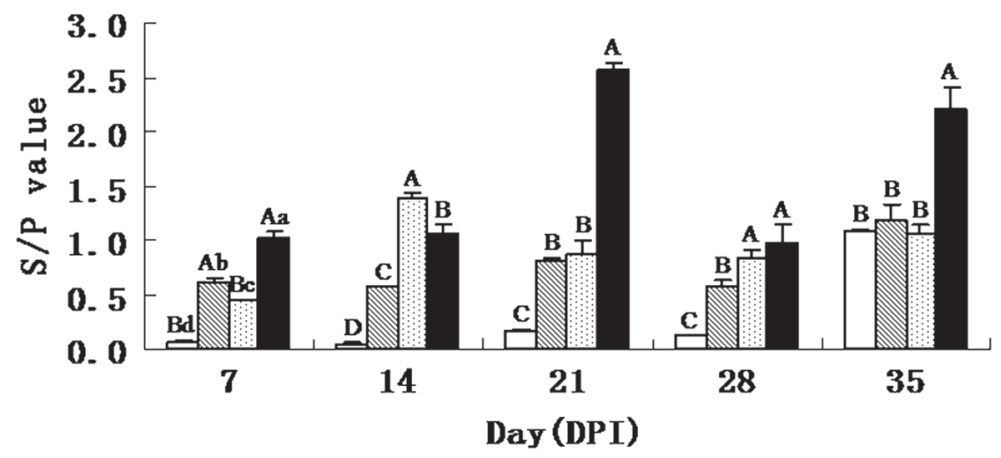

Fig. 4. The $\mathrm{S} / \mathrm{P}$ values of anti-Mhp-specific SIgA in the nasal secretions collected at 7, 14, 21, 28 and 35 days after the first inoculation. Results are presented as the mean \pm SEM. The level of significance is identified by the $P$ value. Capital letters indicate differences at $P<0.01$, and small letters indicate differences at $P<0.05$.

munization may offer alternative routes for prevention of the invasion and colonization of $\mathrm{Mhp}$.

Numerous studies have demonstrated a close relation- ship between the occurrence of mycoplasmal pneumonia of swine and the production of inflammatory cytokines, and tumor necrosis factor- $\alpha$ and increased levels of IL-1, IL-6 
and IL-10 were detected in the bronchoalveolar lavage fluid from infected pigs [8]. The numbers of $\mathrm{CD}^{+}$and $\mathrm{CD} 8^{+} \mathrm{T}$ lymphocytes are important indicators of cellular immunity levels. Our research has shown that intranasal immunization and intrapulmonary immunization with the attenuated Mhp 168 strain alone significantly increased the secretion of IL-6 and IFN- $\gamma$ during the early stage after immunization. Intrapulmonary immunization also significantly increased the secretion of IL-10, and intrapulmonary immunization with $M h p$ significantly increased the numbers of $\mathrm{CD} 4^{+}$and $\mathrm{CD}^{+} \mathrm{T}$ cells present. CD4 ${ }^{+} \mathrm{T}$ cells mainly elicit Th1-type cytokine-mediated immune responses and increase the secretion of IFN- $\gamma$, whereas $\mathrm{CD}^{+} \mathrm{T}$ cells play a key role in the clearance of pathogens. IL- 6 and IL-10 are Th2-type cytokines in nasal secretions that stimulate the host adaptive immunity to eliminate pathogens $[13,20,21]$. IFN- $\gamma$ secreted in the respiratory tract and lung plays an important role against pathogens and in macrophage activation, which is effective in the prevention of Mhp infection [19].

The antibodies produced by IgA-secreting cells and IgGsecreting cells seem to play an important role in protecting animals against infection. IgA-secreting cells, the main immunocompetent cells in local tissues, have been one of the standard indices used to estimate mucosal immunity [25]. sIgA is the principal immunological defense on respiratory mucosal surfaces and prevents effective infection and colonization of invading pathogens [17]. Increased local sIgA levels may play an important role in preventing $M h p$ infection after intranasal or intrapulmonary immunization in pigs [26]. In a previous study, Dr. Shao demonstrated that intrapulmonary immunization could provide protection against a challenge with $M$. hyopneumoniae in pigs [26].

Both intranasal and intrapulmonary vaccinations could increase local cellular and humoral immunity in the respiratory tract. Interestingly, intrapulmonary vaccination increased the levels of IFN- $\gamma$ and sIgA more than intranasal vaccination, which could be explained by the "common mucosal immune system" [9]. According to this theory, all mucosal surfaces are linked together as part of the "common mucosal immune system," and the induction of immune responses at one mucosal site will spread to other mucosal sites. For example, immune responses induced in the gut also affect the mammary gland [3]. Current studies have shown that intranasal immunization with $P R V$ or $P R R S V$ increases the levels of specific antibodies and Th1-type cytokines in the lung [4]. The specific IgA-secreting cells generated in nasal-associated lymphoid tissue can be transferred to other mucosal sites in the respiratory tract to confer wide mucosal protection [6]. Although these observations suggest that an immune network exists within the respiratory system, the mechanism of the immune network is still unclear. A pig model may be a good choice for study of the mucosal immune network [7, 23].

Consistent with Thacker's report, intramuscular immunization with the attenuated $M h p 168$ strain also induced immune responses in the local respiratory tract [19], which may be related to the large numbers of capillaries distributed in the lung. It is easy for $M h p$ to migrate from the muscle tissues to the lung via the blood. The lung has a special anatomical position, located at the juncture of the mucosal immune system and the systemic immune system. However, intramuscular immunization induced local immune responses at a low level. Therefore, it is not effective against the invasion of $M h p$ from the respiratory tract.

In conclusion, we demonstrated that intrapulmonary immunization with the attenuated Mhp 168 strain induces cellular and humoral immune responses in the local respiratory tract. Our data indicate that intrapulmonary immunization with $M h p$ may be a promising route for vaccinating pigs against $M h p$.

\section{CONFLICTS OF INTEREST}

The authors state that they have no conflicts of interest.

ACKNOWLEDGMENTS. This work was supported by grants 31172302 and 31372465 from the National Science Grants of China and the Priority Academic Program Development of Jiangsu Higher Education Institutions (PAPD).

\section{REFERENCES}

1. Barrette, R. W., Szczepanek, S. M., Rood, D., Challa, S., Avery, N., Vajdy, M., Kramer, E., Rodriguez, L. and Silbart, L. K. 2011. Use of inactivated Escherichia coli enterotoxins to enhance respiratory mucosal adjuvanticity during vaccination in swine. Clin. Vaccine Immunol. 18: 1996-1998. [Medline] [CrossRef]

2. Blanchard, B., Vena, M. M., Cavalier, A., Le Lannic, J., Gouranton, J. and Kobisch, M. 1992. Electron microscopic observation of the respiratory tract of SPF piglets inoculated with $\mathrm{Myco-}$ plasma hyopneumoniae. Vet. Microbiol. 30: 329-341. [Medline] [CrossRef]

3. Brandtzaeg, P. 2010. The mucosal immune system and its integration with the mammary glands. J. Pediatr. 156: S8-S15. [Medline] [CrossRef]

4. Dwivedi, V., Manickam, C., Patterson, R., Dodson, K., Weeman, M. and Renukaradhya, G. J. 2011. Intranasal delivery of whole cell lysate of Mycobacterium tuberculosis induces protective immune responses to a modified live porcine reproductive and respiratory syndrome virus vaccine in pigs. Vaccine 29: 40674076. [Medline] [CrossRef]

5. Feng, Z. X., Shao, G. Q., Liu, M. J., Wang, H. Y., Gan, Y. and $\mathrm{Wu}, \mathrm{X}$. S. 2010. Development and validation of a sIgA-ELISA for the detection of Mycoplasma hyopneumoniae infection. Vet. Microbiol. 143: 410-416. [Medline] [CrossRef]

6. Fukuizumi, T., Inoue, H., Anzai, Y., Tsujisawa, T. and Uchiyama, C. 1995. Sheep red blood cell instillation at palatine tonsil effectively induces specific IgA class antibody in saliva in rabbits. Microbiol. Immunol. 39: 351-359. [Medline] [CrossRef]

7. Hein, W. R. and Griebel, P. J. 2003. A road less travelled: large animal models in immunological research. Nat. Rev. Immunol. 3: 79-84. [Medline] [CrossRef]

8. Hwang, M. H., Chang, Z. Q., Kang, E. H., Lim, J. H., Yun, H. I., Rhee, M. H., Jeong, K. S. and Park, S. C. 2008. Surfactin C inhibits Mycoplasma hyopneumoniae-induced transcription of proinflammatory cytokines and nitric oxide production in murine RAW 264.7 cells. Biotechnol. Lett. 30: 229-233. [Medline] [CrossRef]

9. Iijima, H., Takahashi, I. and Kiyono, H. 2001. Mucosal immune 
network in the gut for the control of infectious diseases. Rev. Med. Virol. 11: 117-133. [Medline] [CrossRef]

10. LeRoith, T., Hammond, S., Todd, S. M., Ni, Y., Cecere, T. and Pelzer, K. D. 2011. A modified live PRRSV vaccine and the pathogenic parent strain induce regulatory $\mathrm{T}$ cells in pigs naturally infected with Mycoplasma hyopneumoniae. Vet. Immunol. Immunopathol. 140: 312-316. [Medline] [CrossRef]

11. Li, Y., Li, P., Wang, X., Yu, Q. and Yang, Q. 2012. Co-administration of attenuated Mycoplasma hyopneumoniae 168 strain with bacterial DNA enhances the local and systemic immune response after intranasal vaccination in pigs. Vaccine 30: $2153-$ 2158. [Medline] [CrossRef]

12. Meitin, C. A., Bender, B. S. and Small, P. A. 1994. Enteric immunization of mice against influenza with recombinant vaccinia. Proc. Natl. Acad. Sci. U.S.A. 91: 11187-11191. [Medline] [CrossRef]

13. Morsey, M. A., Van-Kessel, A. G., Mori, Y., Popowych, Y., Godson, D., Campos, M. and Babiuk, L. A. 1999. Cytokine profiles following interaction between bovine alveolar macrophages and Pasteurella haemolytica. Microb. Pathog. 26: 325-331. [Medline] [CrossRef]

14. Newman, S. P., Pitcairn, G. R. and Dalby, R. N. 2004. Drug delivery to the nasal cavity: in vitro and in vivo assessment. Crit. Rev. Ther. Drug Carrier Syst. 21: 21-66. [Medline] [CrossRef]

15. Pabst, R. 1990. Compartmentalization and kinetics of lymphoid cells in the lung. Reg. Immunol. 3: 62-71. [Medline]

16. Richardson, J. S., Abou, M. C., Tran, K. N., Kumar, A., Sahai, B. M. and Kobinger, G. P. 2011. Impact of systemic or mucosal immunity to adenovirus on Ad-based Ebola virus vaccine efficacy in guinea pigs. J. Infect. Dis. 204: S1032-S1042. [Medline] [CrossRef]

17. Straw, B., Zimmerman, J. and D'Allaire, S. D. T. 1999. pp. 505-520. Diseases of Swine. 8th ed., Iowa State University Press, Ames.

18. Sullivan, V. J., Mikszta, J. A., Laurent, P., Huang, J. and Ford, B. 2006. Noninvasive delivery technologies: respiratory delivery of vaccines. Expert Opin. Drug Deliv. 3: 87-95. [Medline] [CrossRef]
19. Thacker, E. L., Thacker, B. J., Kuhn, M., Hawkins, P. A. and Waters, W. R. 2000. Evaluation of local and systemic immune responses induced by intramuscular injection of a Mycoplasma hyopneumoniae bacterin to pigs. Am. J. Vet. Res. 61: 1384-1389. [Medline] [CrossRef]

20. Van Reeth, K., Labarque, G., Nauwynck, H. and Pensaert, M. 1999. Differential production of proinflammatory cytokines in the pig lung during different respiratory virus infections: correlations with pathogenicity. Res. Vet. Sci. 67: 47-52. [Medline] [CrossRef]

21. Van Reeth, K., Van Gucht, S. and Pensaert, M. 2002. In vivo studies on cytokine involvement during acute viral respiratory disease of swine: troublesome but rewarding. Vet. Immunol. Immunopathol. 87: 161-168. [Medline] [CrossRef]

22. Wee, J. L., Scheerlinck, J. P., Snibson, K. J., Edwards, S., Pearse, M., Quinn, C. and Sutton, P. 2008. Pulmonary delivery of ISCOMATRIX influenza vaccine induces both systemic and mucosal immunity with antigen dose sparing. Mucosal Immunol. 1: 489-496. [Medline] [CrossRef]

23. Yen, H. H., Wee, J. L., Snibson, K. J. and Scheerlinck, J. P. 2009. Thoracic duct cannulation without thoracotomy in sheep: a method for accessing efferent lymph from the lung. Vet. Immunol. Immunopathol. 129: 76-81. [Medline] [CrossRef]

24. Zhang, H., Lunney, J. K., Baker, R. B. and Opriessnig, T. 2011. Cytokine and chemokine mRNA expression profiles in tracheobronchial lymph nodes from pigs singularly infected or coinfected with porcine circovirus type 2 (PCV2) and Mycoplasma hyopneumoniae (MHYO). Vet. Immunol. Immunopathol. 140: 152-158. [Medline] [CrossRef]

25. Zhang, X. and Yang, Q. 2007. Effect of compound mucosal immune adjuvant on mucosal and systemic immune responses in chicken orally vaccinated with attenuated Newcastle-disease vaccine. Vaccine 25: 3254-3262. [Medline] [CrossRef]

26. Feng, Z., Shao, G., Liu, M., Wu, X., Zhou, Y. and Gan, Y. 2010. Immune responses to the attenuated Mycoplasma hyopneumoniae 168 strain vaccine by intrapulmonic immunization in piglets. Agric. Sci. China 9: 423-431. [CrossRef] 